RU Эффективность обучения иностранному языку в вузе: компоненты эмоционального и интеллектуального

\author{
Мельничук М. В., Калугина О. А.
}

\begin{abstract}
Аннотация. Цель исследования - определение компонентов эффективности обучения иностранному языку в вузе. В статье рассмотрены факторы, компоненты и критерии эффективности обучения иностранному языку в вузе; обоснована актуальность учета не только количественных, но и качественных составляющих эффективности обучения иностранному языку в вузе в условиях глобализации и цифровизации академической среды вуза. Научная новизна работы выражена в конструировании структурно-содержательных компонентов эффективности обучения иностранному языку в вузе, сочетающих в себе элементы эмоционального и интеллектуального. В результате предложены структурно-содержательные компоненты эффективности обучения иностранному языку в вузе, четкое понимание которых будет способствовать объективности со стороны профессорско-преподавательского состава и качественным результатам языковой подготовки у студентов вуза.
\end{abstract}

\title{
EN Efficiency of Higher School Language Education: Emotional and Intellectual Aspects
}

\author{
Melnichuk M. V., Kalugina O. A.
}

\begin{abstract}
The article considers the following issues: factors, components and criteria of higher school language education efficiency. The paper justifies the thesis that under the conditions of globalization and digitalization of higher school academic environment, both quantitative and qualitative aspects of language education efficiency should be taken into account. Scientific originality of the study lies in the fact that the authors determine structural and meaningful components of language education efficiency taking into account emotional and intellectual aspects. The research findings are as follows: the authors determine language education efficiency structure, clear understanding of which helps to ensure objectivity of knowledge assessment and to improve quality of students' linguistic training.
\end{abstract}

\section{Введение}

Актуальность темы исследования обусловлена тем, что в настоящее время в современной России осуществляется процесс стремительной цифровизации и глобализации. Остро стоит вопрос об обеспечении эффективности обучения иностранным языкам (ИЯ) студентов высшей школы. Современные достижения науки и практики ставят перед специалистами нового поколения нестандартные задачи, которые невозможно решить, придерживаясь старых критериев, методов, форм и принципов работы и обучения.

Доступ к большим потокам информации, который даёт возможность повысить общий уровень интеллекта обучающегося, заключающегося в глубоких знаниях, эрудиции, способности логично мыслить в целом, который непосредственно связан с профессиональной успешностью личности, является недостаточным. Современная динамическая образовательная среда должна быть направлена как на развитие общего интеллекта, так и на возможности социализации и адаптации, понимания межкультурной коммуникации, формирование и развитие эмоциональных компонентов личности.

Более того, достижение целей устойчивого развития предполагает сосредоточение внимания не только на финансовых, социальных, экологических и научных аспектах, но и развитии эмоциональных компетенций граждан, которые определяют основу для принятия решений и действий. Формирование личности - это взаимодействие когнитивных, физических, лингвистических, социальных, аффективных и эмоциональных факторов, измерений и областей, причем последние очень важны в образовании. Языковое образование в интересах устойчивого развития будет эффективным только в том случае, если оно будет применять иное

Научная статья (original research article) । https://doi.org/10.30853/phil210403

(๔ 2021 Авторы. ООО Издательство «Грамота» (๔ 2021 The Authors. GRAMOTA Publishers). Открытый доступ предоставляется на условиях лицензии СС ВY 4.0 (open access article under the CС BY 4.0 license): https://creativecommons.org/licenses/by/4.0/ 
представление о человечестве, обществе, жизни и природе. Кроме того, иное видение образования заключается в фокусе на гармонию с самим собой и окружающими. Это требует иной антропологии и этики, когда студенты не только приобретают компетенции, направленные на устойчивое развитие и связанные с их учебой, но и приобретают межкультурные компетенции, эмоциональные компетенции в процессе обучения. Данные трансверсальные компетенции имеют решающее значение в глобальном технологическом обществе [17].

С дидактических позиций осмысление теоретико-методологических подходов к определению эффективности обучения ИЯ, с учетом эмоциональных компетенций, создаст необходимые условия для реализации основных приоритетных направлений высшего образования в условиях глобальной цифровизации.

На наш взгляд, проблема отсутствия унифицированного определения к понятию эффективности обучения в целом, недооценки эмоциональных критериев в системе мониторинга эффективности обучения ИЯ студента требует исследования и является актуальной в процессе модернизации системы высшего образования в свете новых тенденций, направленных на построение цифровой образовательной среды в реалиях межкультурной коммуникации.

В соответствии с поставленной целью в данной научной статье решаются следующие задачи:

1) обзор теоретических подходов ученых к определению сущности понятия эффективности обучения ИЯ;

2) анализ теоретико-методологических подходов к определению компонентов эффективности обучения ия в высшей школе;

3) конструирование структурно-содержательных компонентов эффективности обучения ИЯ в вузе.

В статье применяются следующие методы исследования: методы изучения и исследования научной литературы, описательный метод, метод синтеза, обобщения и проектирования.

Теоретической базой исследования послужили труды ученых по педагогике общего образования, высшей школы и психологии (Л. С. Выготский [4], А. Н. Леонтьев [9], С. Л. Рубинштейн [12], В. А. Якунин [15], Л. М. Эррера [13], И. М. Котов [8], А. Ю. Клыбин [7], А. А. Караванов [5]), посвященные вопросам эффективности обучения в высшей школе и сочетания когнитивного и эмоционального в учебной деятельности. Учитывались работы по проблемам методики преподавания иностранных языков в вузе (Л. П. Варенина [2], Д. Г. Васьбиева [3], С. Г. Кибасова [6]).

Практическая значимость исследования заключается в том, что проанализированные в статье теоретикометодологические подходы к эффективности обучения ИЯ студента с учетом эмоционального компонента позволят конкретизировать качественные и количественные параметры целей обучения в высшей школе; смогут дополнить нормы функционирования педагогической системы с учетом эмоциональных критериев; выявить их потенциал для обеспечения результативности обучения в соответствии с действующими условиями, федеральными государственными образовательными стандартами высшего образования (ФГОС ВО) и требованиями общественности.

\section{Эффективность обучения иностранным языкам в высшей школе}

Эффективность обучения (ЭО) - мера соответствия достигнутых реальных результатов поставленным целям образовательной программы [14].

Термин ЭО в целом связан с качеством обучения, которое определяется как соответствие фактического уровня и качества подготовки выпускников требованиям ГОС и параметрам профессионального обучения [11].

В английском языке можно выделить следующие слова, которые описывают понятие эффективности: efficiency (рациональное использование времени и энергии), effectiveness (степень эффективности), efficaсу (способность метода достижения привести к желаемому результату) [16]. Ключевыми аспектами в данном определении являются цель и результат языкового обучения.

Эффективность обучения ИЯ рассматривается также через такие концепты, как «производственный процесс» и «полезность». Производственный процесс образования состоит из четырех основных факторов: вложений, процесса, отдачи и результатов. Вложения - это ресурсы, которые используются в производственной деятельности. Для образовательного процесса ресурсы могут быть разделены на общие категории характеристик обучаемого, учебного заведения, преподавателя, учебного материала и оборудования, а также характеристики средств обучения. В каждом случае термин «характеристика» относится к доступности ресурса, его характеру и качеству, его способу и степени использования [18].

Исходя из представленных определений, необходимо понимать цели эффективного обучения ИЯ, результаты, ресурсы, используемые высшей школой на данном этапе. Обратимся к ФГОС ВО (3++) по направлениям бакалавриата и ФГОС ВО (3++) по направлениям магистратуры [10]. Независимо от наименования направления согласно стандартам наряду с общепрофессиональными компетенциями отмечается значимость универсальных компетенций (УК) будущего специалиста. В качестве примера можно привести системное и критическое мышление, разработку и реализацию проектов, командную работу и лидерство, коммуникацию, межкультурное взаимодействие, самоорганизацию и саморазвитие (в том числе здоровьесбережение). Следовательно, на государственном уровне признаётся значимость формирования не только профессиональных качеств выпускника, но и личностных качеств, базирующихся на межкультурном взаимодействии, умении общаться на иностранном языке; важность не только количественных характеристик, выраженных в знаниях, умениях и навыках, но и качественных составляющих, направленных на формирование личностно-ценностных характеристик. 


\section{Обзор теоретических подходов ученых к определению компонентов эффективности обучения иностранным языкам}

Сочетание интеллектуальных и личностных характеристик, нацеленных на эффективный процесс обучения ИЯ, нашло отражением в ряде научных зарубежных и отечественных подходов.

Среди отечественных ученых, которые занимались вопросами взаимодействия аффективного и интеллектуальных процессов, были Л. С. Выготский, С. Л. Рубинштейн, А. Н. Леонтьев [4; 9; 12].

Так, Л. С. Выготский полагал, что личность - единство интеллекта и аффекта. Их отношение - «не вещь, а процесс» [4]. С. Л. Рубинштейн отмечал, что эмоции человека - это единство эмоционального и интеллектуального. Познавательные процессы, по мнению ученого, также являются единством интеллектуального и эмоционального. Данные процессы находятся в зависимости от компонентов конкретной жизни и деятельности индивида [12]. В нашем случае под деятельностью индивида нами понимаются образовательная деятельность и учебный процесс. А. Н. Леонтьев также считал, что общение, творчество, познание, запоминание получают регулирование в форме эмоциональных процессов. Невозможно представить безэмоциональную регуляцию деятельности [9].

А. А. Караванов в основу исследований эффективности обучения включает психологические изменения и результаты, которые формируются в процессе управляемой учебно-познавательной деятельности. Предстоящий психологический результат выражен в качественных и количественных параметрах. По мнению А. А. Караванова, понятия «академическая успеваемость» и «учебная успешность» синонимичны понятиям «результативность образования» и «эффективность образования». Относительно обучения в высшей школе социально значимые психологические качества выпускника, его профессиональная компетентность и умения являются психологическим результатом. Несмотря на то, что внутренние содержательные критерии оценки ЭО в вузе, такие как общая и профессиональная компетентность, учебная мотивация, активность, творчество, самоуправление, самостоятельность, довольно независимы и являются значимыми, ученый говорит о важности единого критерия - академической успеваемости. Однако учет только внутренних критериев является недостаточным. Должны учитываться внешние критерии эффективности обучения в высшем учебном заведении. Производственная адаптация выпускника, профессиональная устойчивость, способность овладевать профессиональным мастерством, служебная карьера относятся к их числу [5].

Ученые, занимающиеся методикой преподавания ИЯ, видят эффективность обучения ИЯ в активной интеграции в учебный процесс элементов smart-education, которые предоставлены информационными технологиями (podcast, web-quest, multimedia scrapbooks), а также сочетании традиционных и нетрадиционных методов обучения ИЯ (метод грамматического перевода, прямое изучение, аудиолингвализм, суггестопедический метод, «тихий» метод, метод изучения сообществом, коммуникативный метод, принципиальный эклектизм); построение индивидуальной траектории студента, ориентированной на будущую профессию [2; 3, с. 940; 6, с. 145].

Рассматривая проблему повышения эффективности обучения студентов негосударственных вузов, И. М. Котов выделил следующие критерии оценки ЭО: содержательно-целевой; качество учебной информации; темповременной; результативно-практический. В диссертационном исследовании были учтены факторы, которые присутствуют в образовательном процессе: личностные факторы обучающихся, личностно-профессиональные факторы педагогов, факторы, воздействующие на организацию, содержание и методику образовательного процесса. Повышение ЭО ученый видит в совершенствовании организации обучения студентов и улучшении методического обеспечения процесса обучения. Фокус данного исследования - на процессе обучения [8].

А. Ю. Клыбин, работая над проблематикой эффективности профессионального обучения, уделяет внимание комплексности данного вопроса и доказывает необходимость разработки критериально-оценочного комплекса системы оценки эффективности профессионального обучения. Данный комплекс учитывает не только результат, но и процесс обучения и включает аналитико-прогностический, мотивационно-целевой, формирующий, проектировочный, результативный, операционально-диагностический компоненты. ЭО студентов выражена в умении ставить цели обучения; разрабатывать содержание обучения, грамотно использовать и подбирать методы и средства обучения. Результаты эффективного обучения отражены в уровне усвоения содержания учебного материала, в познавательной активности и деятельности студентов, степени личностного их развития [7].

Анализируя факторы эффективности профессионального обучения в вузе, С. Алексеева, О. Назарова также отмечают значимость таких факторов, как адекватность программ обучения настоящим и будущим потребностям организации; корректная формулировка целей обучения; использование правильных форм и методов обучения; степень учета возрастных особенностей при проведении обучения; мотивация к обучению. Ученые отмечают, что важный этап процесса определения ЭО - установление критериев оценки [1].

В. А. Якунин конечной целью обучения в высшей школе считал удовлетворенность студента избранной им профессией. В мотивационно-целевом обучении уровень мотивации является значимым критерием учебного процесса. В. А. Якунин относит к критериям ЭО способность студента к самоуправлению в различных формах его проявления. Это может быть выражено в постановке целей, изменении целей, готовности к самообразованию, самостоятельному принятию решений, способности к самоорганизации, самоконтролю и саморегуляции, осуществлении коммуникативной деятельности. В. А. Якунин и А. А. Караванов едины в суждении, что данные критерии отражены в универсальном критерии - академической успеваемости студента. Результат обучения отражен в балле/оценке. Для уточнения методов обучения, повлиявших на уровень успеваемости, используют термин «учебная успешность». Б. Г. Ананьев ввел данное понятие. Были определены показатели 
учебной успешности: напряженность, стили учебной работы, степень усилий, затраченных обучаемым для достижения данных результатов, темп обучения. Следовательно, понятия «результативность» и «эффективность» аналогичны терминам «академическая успеваемость» и «учебная успеваемость» [15].

Л. М. Эррера рассматривает эффективность обучения через призму мотивационных компонентов и отождествляет данное понятие с получением качественных знаний и готовностью обучаться на хорошие оценки. В результате данного исследования выявлены не только материальные составляющие эффективного обучения, такие как получение стипендии и обеспечение работой после завершения вуза, но и социально-психологические компоненты, включающие силу воли, интерес, вызванный грамотно организованным содержанием учебнометодических материалов и организацией учебного процесса, выраженной равномерной нагрузкой по дням недели, признание выполненной работы, например, похвалу преподавателя; страх перед сдачей экзаменов [13].

Рассмотренные подходы связаны в основном с концепцией личностно ориентированного языкового обучения и опираются на принципы вариативности, синтеза интеллекта, аффекта и действия, приоритетного старта. Учитывая данные характеристики, предложим структурно-содержательные компоненты эффективности обучения ИЯ в вузе, содержащие эмоциональные и интеллектуальные компоненты.

\section{Структурно-содержательные компоненты эффективности обучения иностранным языкам в вузе}

В научных работах наблюдается тенденция к синергии подходов когнитивного и эмоционального языкового обучения, направленных на повышение образовательного результата при достижении эффективности обучения ИЯ, выраженной в формировании гармоничной личности, способной к самоорганизации, самопознанию, выполнению задач, нравственно устойчивой и обладающей высоким уровнем иноязычной профессиональной компетентности.

Интегрируя конструктивные компоненты сложившихся подходов к изучению эффективности обучения ИЯ в высшей школе, мы предложили структурно-содержательные компоненты эффективности обучения ИЯ в вузе, включающие компоненты интеллектуально и эмоционального (Рис. 1).

Интеллектуальный компонент выражен в критерии академической успеваемости, включающем такие характеристики, как уровень усвоения содержимого языкового материала; познавательная активность и деятельность; стиль учебной работы; степень усилий, которые приложены студентом для приобретения иноязычной коммуникативной компетентности; временные затраты, затраченные на изучение учебного материала и совершенствование приобретаемых компетенций. Эмоциональный компонент ЭО охарактеризован внутренними критериями, такими как мотивация студента к учебной деятельности; готовность затрачивать усилия с целью получения учебной информации и активность; умение творчески и креативно подходить к решению учебных задач, посредством гибкости мыслительных процессов; способность самостоятельно оценить уровень своих знаний, умений, навыков и компетенций; умение управлять своей учебной деятельностью (ставить учебные цели и оценивать полученный результат); самостоятельность, готовность к самообучению, выраженная в адекватном выборе методов, форм обучения ИЯ, источников получения учебной информации; способность видеть возможности для личностного и профессионального развития; владение различными видами коммуникации на иностранном языке, характеризуемое умением общаться, находить компромиссные решения, работать в команде; способность использовать силу воли как ресурс мобилизации своих интеллектуальных способностей для достижения академической успешности; вовлеченность студента в учебный процесс; интерес к познавательной деятельности.

Компоненты эффективности обучения ИЯ (интеллектуальное и эмоциональное) взаимосвязаны между собой и обусловлены следующими факторами: качественными образовательными программами, включающими высокий уровень владения ИЯ, которые соответствуют образовательным стандартам и позволяют студенту выстраивать обучение по различным траекториям с учетом индивидуальных потребностей; формулирование конкретных целей и их прямая связь с содержанием языкового обучения; рациональные формы/методы обучения ИЯ, сочетание традиционных и инновационных методов и методическая готовность педагогов применять данные методы в академической языковой среде; учет психолого-возрастных характеристик с целью активизации познавательной деятельности студента.

Четкое понимание преподавателями и студентами структурно-содержательных компонентов эффективности обучения ИЯ в вузе будет способствовать объективной оценке уровня профессиональной иноязычной коммуникативной компетентности на различных этапах обучения.

Конструирование структурно-содержательных компонентов эффективности обучения ИЯ в вузе дает возможность перейти на более качественный уровень обучения ИЯ в высшей школе.

Отождествление эффективности обучения ИЯ в вузе только лишь с количественными показателями, выраженными в академической успеваемости баллами и оценками по дисциплинам языковой подготовки, является недостаточным в условиях формирования всесторонне развитой гармоничной личности, которой предстоит работать в условиях цифровой экономики и межкультурной коммуникации.

Необходимость четкого формирования критериев эффективности обучения ИЯ продиктована целями, определяемыми государством, обществом, условиями реализации учебного процесса. Возможны отрицательные результаты при неадекватной формулировке критериев и односторонности определения критериев эффективности обучения ИЯ. Следовательно, очевидна необходимость во введении «качественных критериев» в систему эффективности обучения ИЯ в вузе, содержащих наряду с интеллектуальными компонентами эмоциональные составляющие. 


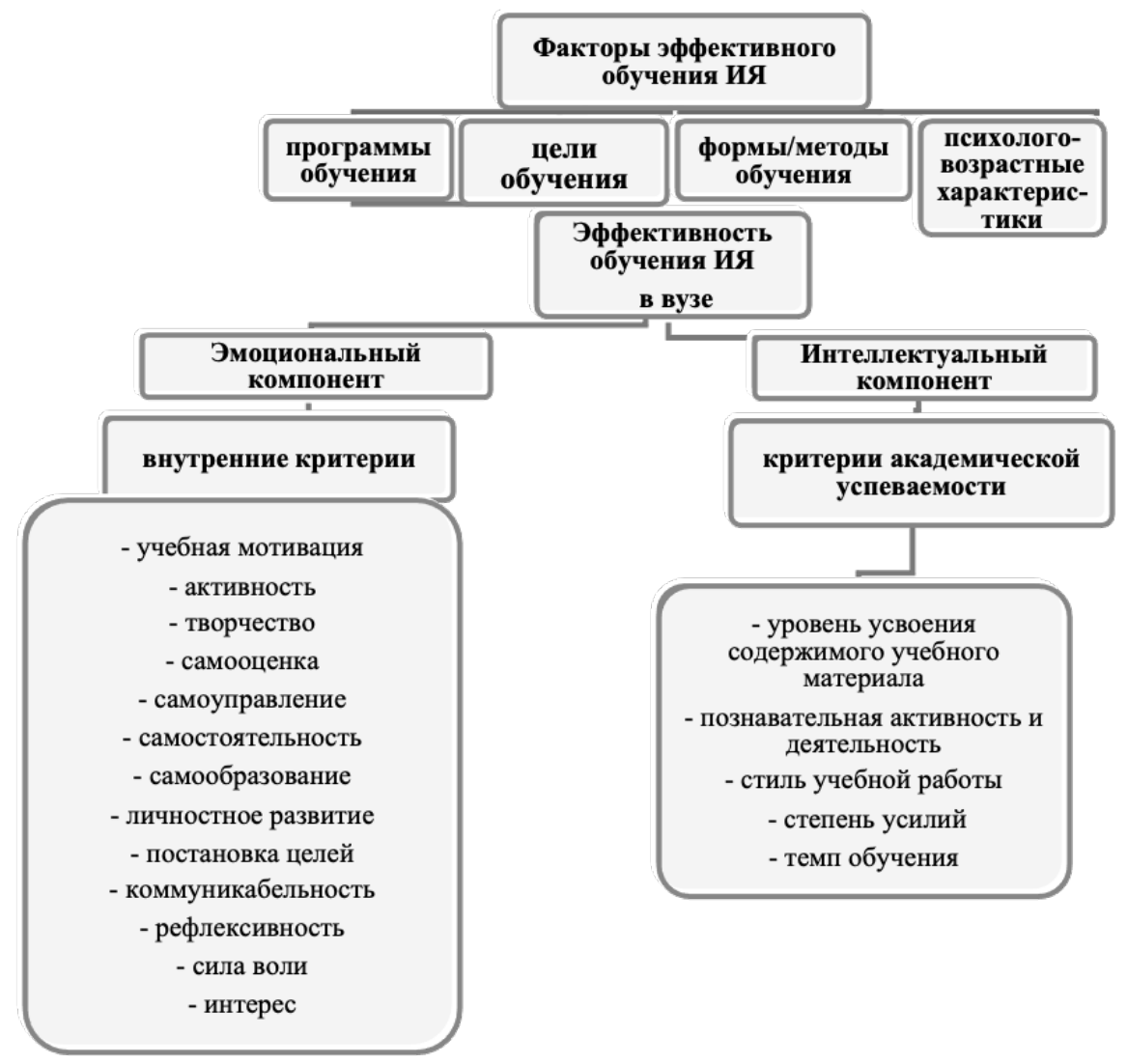

Рисунок 1. Структурно-содержательные компоненты эффективности обучения ИЯ в вузе. Источник: составлено авторами

\section{Заключение}

Проведенное исследование позволяет сделать следующие выводы.

Сущность понятия эффективность обучения ИЯ заключается в определении результата и достижении поставленной цели как на отдельном этапе обучения в высшей школе, так и в процессе академической деятельности в вузе в целом. Положительному результату обучения ИЯ в вузе способствуют соответствие содержания обучения целям обучения по дисциплинам языковой подготовки, ГОС ВО, квалификационным требованиям, составу профессиональной деятельности выпускника; объем содержания, полнота научной и учебной информации, уровень новизны содержания, доступность содержания, структурно-логическая упорядоченность, которые отражены в программах обучения, методах и формах обучения ИЯ в вузе.

Теоретико-методологические подходы (компетентностный, личностно ориентированный, аксиологический) к определению компонентов эффективности обучения ИЯ в высшей школе позволили выявить ряд структурно-содержательных компонентов эффективности обучения ИЯ в вузе, включающих эмоциональные и интеллектуальные составляющие. Четкое описание критериев (внутренние критерии и критерии академической успеваемости), характеризующих каждый компонент, систематизирует процесс мониторинга качества обучения ИЯ, ориентирует педагогов и студентов не только на знания, умения и навыки, но и на личностные качества обучаемого (коммуникабельность, сила воли, интерес, мотивированность и т.д.), что весьма значимо в профессиональной подготовке будущего специалиста.

Перспективы дальнейшего исследования мы видим в разработке модели эффективности обучения ИЯ в вузе, учитывающей эмоциональный и интеллектуальный компоненты, а также современные реалии цифровизации образовательной системы высшей школы и специфику российского высшего образования. Поскольку качество и эффективность российского высшего образования напрямую оказывают влияние на благосостояние государства и её граждан, настоящее исследование открывает широкое поле для дальнейших исследований.

\section{Финансирование | Funding}

RU Статья подготовлена по результатам исследований, выполненных за счет бюджетных средств по государственному заданию Финансовому университету при Правительстве Российской Федерации на 2021 г. 


\section{Источники | References}

1. Алексеева С., Назарова О. Факторы обучения эффективности в вузе [Электронный ресурс]. URL: https://cyberleninka.ru/article/n/faktory-effektivnosti-obucheniya-v-vuze (дата обращения: 09.07.2021).

2. Варенина Л. П. Эффективность смешанного метода обучения иностранному языку в неязыковом вузе // Вестник Московского государственного гуманитарного университета им. М. А. Шолохова. Педагогика и психология. 2012. № 2. С. 48-52.

3. Васьбиева Д. Г. Построение индивидуальной траектории обучения студентов иностранному языку в интересах устойчивого развития образовательной системы // Филологические науки. Вопросы теории и практики. 2021. T. 14. № 3. С. 939-944.

4. Выготский Л. С. Психология развития человека. М.: Смысл; Эксмо, 2005. 1136 с.

5. Караванов А. А. Критерии эффективности учебной деятельности студентов [Электронный ресурс]. URL: https://cyberleninka.ru/article/n/kriterii-effektivnosti-uchebnoy-deyatelnosti-studentov (дата обращения: 27.02.2021).

6. Кибасова С. Г. Эффективность традиционных и нетрадиционных методов обучения иностранному языку в экономическом вузе // Профессионально-ориентированное обучение языкам: реальность и перспективы: сборник статей участников Всероссийской научно-практической конференции. СПб., 2018. С. 144-150.

7. Клыбин А. Ю. Дидактическая система оценки эффективности профессионального обучения студентов в вузе: автореф. дисс. ... к. пед. н. Н. Новгород, 2013. 25 с.

8. Котов И. М. Повышение эффективности обучения студентов негосударственных вузов: автореф. дисс. ... к. пед. н. М.: Военный университет, 2003. 28 с.

9. Леонтьев А. Н. Лекции по общей психологии [Электронный ресурс]: учеб. пособие для вузов по спец. «Психология» / под ред. Д. А. Леонтьева, Е. Е. Соколовой. М.: Смысл, 2000. 509 с. URL: http://window.edu.ru/ resource/328/42328/files/index.html (дата обращения: 28.02.2021).

10. Портал Федеральных государственных образовательных стандартов высшего образования [Электронный pecypc]. URL: http://fgosvo.ru/fgosvo/152/150/25 (дата обращения: 28.02.2021).

11. Профессионально-педагогические понятия [Электронный ресурс]: словарь / под ред. Г. М. Романцева. URL: https://didacts.ru/slovari/professionalno-pedagogicheskie-ponjatija-slovar-2005.html (дата обращения: 13.03.2021).

12. Рубинштейн С. Л. Основы общей психологии [Электронный ресурc]. URL: http://yanko.lib.ru/books/psycho/ rubinshteyn=osnovu_obzhey_psc.pdf (дата обращения: 27.02.2021).

13. Эррера Л. М. Эффективность обучения студентов в вузе: мотивация и препятствия // Известия Тульского государственного университета. Педагогика. 2015. № 3. С. 89-93.

14. Эффективность обучения [Электронный ресурс]. URL: https://sberbank-university.ru/edutechclub/glossary/900/(дата обращения: 27.02.2021).

15. Якунин В. А. Педагогическая психология: учеб. пособие / Европ. ин-т экспертов. СПб.: Изд-во Михайлова В. А.; Полиус, 1998. 639 с.

16. Cambridge Dictionary [Электронный ресурс]. URL: https://dictionary.cambridge.org/ru (дата обращения: 28.02.2021).

17. Estrada M., Monferrer D., Rodríguez A., Moliner M. A. Does emotional intelligence influence academic performance? The role of compassion and engagement in education for sustainable development // Sustainability (Switzerland). 2021. Vol. 13. № 4. C. 1-18.

18. Windham D. M. Indicators of Educational Effectiveness and Efficiency [Электронный ресурc]. URL: https://files. eric.ed.gov/fulltext/ED351784.pdf (дата обращения: 07.03.2021).

\section{Информация об авторах | Author information}

RU Мельничук Марина Владимировна ${ }^{1}$, д. экон. н., проф.

Калугина Ольга Анатольевна ${ }^{2}$

1,2 Финансовый университет при Правительстве Российской Федерации, г. Москва

EN Melnichuk Marina Vladimirovna ${ }^{1}, \mathrm{Dr}$

Kalugina Olga Anatolevna ${ }^{2}$

${ }^{1,2}$ Financial University under the Government of the Russian Federation, Moscow

${ }^{1}$ mvmelnichuk@fa.ru, ${ }^{2}$ kaluginaruc@mail.ru

\section{Информация о статье | About this article}

Дата поступления рукописи (received): 16.07.2021; опубликовано (published): 15.09.2021.

Ключевые слова (keywords): эффективность обучения; эмоциональный компонент; интеллектуальный компонент; критерии эффективности; факторы эффективности обучения; teaching efficiency; emotional component; intellectual component; efficiency criteria; educational efficiency factors. 